\title{
Study on Enterprise Innovation Ecosystem and Independent Innovation Strategy under New Normal
}

\author{
Cheng Zhang ${ }^{1, \text { a }}$ \\ ${ }^{1}$ Shunde Polytechnic, Foshan, Guangdong, 528000 \\ ${ }^{a}$ email
}

Keywords: New Normal; Enterprise Innovation Ecosystem; Independent Innovation Strategy

\begin{abstract}
In the context of the new normal, independent innovation of enterprises have a direct impact on their production and development, in the process, companies can be innovative as an ecological system, through changes to the system and the organization of each enterprise resource integration, guaranteed to create a good environment for development, to enable enterprises to gain the ability of independent innovation, in the case of enhanced competitiveness of enterprises, can effectively improve the efficiency of the innovation ecosystem of enterprises laid a good foundation for its development.
\end{abstract}

\section{Introduction}

In the process of enterprise development of the section, knowledge and economic development is more important, in the case study of the ecosystem, innovation strategy, the innovation effect ecosystems are effectively enhance the formation level in the material and energy interchange analysis of dynamic feedback of the ecosystem, and then build a new ecosystem.

\section{The Principle and Evaluation of Enterprise Innovation Ecosystem}

Ecosystem is based on the biological characteristics of the natural environment survival and development, the formation of a more physiological characteristics of the law, in order to develop good habits. Research scientists believe that the natural environment including eco-junction structure and ecological functions, to a certain extent, can effectively study the natural form of all life. Study of ecological theory is the business nature and society, the way research is the use of natural and social sciences to understand the ecological environment. Formation of ecology, is the utilization of living organisms react with the living environment and between organisms, from the perspective of protecting the natural environment and the ecological point of view, to promote the sustainable development of society. Meanwhile, economists study found ecology and ecological environment in the organization's life has similarities to follow enterprise ecology theory also follow the principle of winning a little jig at the same time, there are also many deficiencies, relevant to the needs the researchers studied its efforts to ensure that innovation can be the enterprise ecosystem, thus promoting the progress of enterprises [1].

Currently, the increasingly fierce market competition, the country's policy and technology have begun to change, which leads to the living environment and the development environment of enterprises affected, enterprises must make sound decisions based on internal and external uncertainties. Therefore, companies must build a similar ecological and natural ecosystems, ensure that there is competition mechanism of operation, not only need to follow the principle of parasitic, symbiotic also consider matters only better implementation of innovative work, in order to effectively enhance their ability to innovate, make out innovation ecosystem has certain advantages, on the basis of mutual cooperation on various elements, and form a healthy development of the state. Innovation in the enterprise ecosystem processes, managers should take advantage of mutual restraint manner common growth and development, not only can effectively enhance their own economic benefit, but also to achieve the effect of a good cycle, in order to enhance their competitiveness [2]. 
In the process of enterprise innovation ecosystems, we should pay attention to the evaluation of innovation, use of advanced technology can guarantee, mathematical models and other ways of ecological innovation system of enterprise strategic analysis. In this case, in order to effectively establish the mathematical model, we should choose DEA model, mainly because of its relatively good performance, can be widely used in innovative work, coupled with a number of experts was carried out effective improvement, Therefore, enterprises should use DEA model to implement innovative assessment, evaluation principle: create two virtual decision-making unit, and on behalf of the enterprise eco-innovation part of the best and the worst unit, and then the implementation of decision-making, to ensure that can enhance input output and efficiency. Ecological innovation enterprise, the evaluation value of each DMU is more important, business-related and technical personnel must be on the evaluation value is analyzed and sorted from high to low, and then developed eco-innovative ways to facilitate the implementation of the next step study [3].

\section{Enterprise Innovation Ecosystem Assessment under the New Normal}

In the course of the ecological environment evaluation of business innovation, the technician can use the basic data analysis mode of implementation, to ensure that enterprises can promote rapid progress. In an industrial park for the research unit, choose moderate industrial park in the city's competitiveness and the local economic development play an important role. At the time of the investigation for the study of business, technical personnel must pay attention to their overall level of innovation and strategic planning situation, and thus enhance the efficiency of regional development, play a particular advantage. The survey matters, the technician take questionnaire its investigation, DEA and then apply the above mentioned method proven to enhance the efficiency in the delivery of the questionnaire process, according to investigators for dozens of companies research, a total of recover the 30 questionnaires, following scientific, rational analysis, and finally 20 questionnaires effectively enhance efficiency, even up to 70\% [4].

Technical staff to develop an analytical model using C2R model data help in ensuring the quality of the output data based on the actual investment generated reference DMU program data, if researchers were to factor proportions decision to set a minimum value of $R$, then when $R$ is less than one time, it means DMU can reduce the investment project, and the value of $\mathrm{R}$ to the normal data showed the opposite state, to ensure better control of input factors to enhance efficiency. If $\mathrm{R}$ is equal to one, then the plurality of elements, at least one element has reached a minimum, it means DMU had almost expired. Finally, the relevant management personnel in accordance with the actual situation of DEA, and an analysis of the C2R model, guaranteed effective solution model data, and ultimately get the efficiency value, and to determine the model in enterprise innovation ecosystem environment process, whether there is value in use [5] .

In the process of implementation of the evaluation work in accordance with all companies DMU RMS survey shows that at least four units in a high level of innovation efficiency value extent, to ensure better development of $\mathrm{Xu}$ Jinguo home, while for innovation less efficient units, innovation or should be corrected, thereby enhancing the competitiveness of enterprises, so that in the fierce competition in the market to effective development [6].

At present, enterprises in the process of innovation and ecological environment, the main application of the BCC model analysis to further expand the scale of the ecological environment for enterprise innovation, correlation analysis personnel should pay attention to the following points: Firstly, to calculate the effectiveness of the DMU reasonable model then draw scale data, the size of the case come to innovation, and the relevant personnel according to the size of the data input efficiency of the enterprise innovation discretion when, to a certain extent, can effectively calculate enterprise output ratio. Second, the introduction of advanced technology, the concept of V0, the boundaries of data analysis is set to 0 if $\mathrm{V} 0$ is less than 0 , then that represents innovation and economies of scale in the development of the enterprise is more unfavorable, gradually showing a decreasing trend, companies to some extent, there is the problem of blind investment, can not effectively enhance their economic viability. If $\mathrm{V} 0$ is greater than 0 , then the economic benefits of innovative enterprises is in growth mode, indicating that business investment is more effective and 
can effectively enhance the competitiveness of enterprises. If $\mathrm{V} 0$ is equal to 0 , then it shows economic efficiency of enterprises has been in the same situation [7].

In the analysis of the ecological system of several companies creating innovation in the process, found that its economic benefits and the size has not changed, it shows that in the present case, the economic efficiency of enterprises has been maximized, rope several companies in the time scale of innovation, the emergence of the phenomenon of diminishing economic returns, unable to effectively enhance the size of the business, adversely affecting their development, which requires companies in the implementation of ecological innovation, the need to increase investment to ensure better able to manage the funds invested, and thus enhance the economic efficiency of enterprises [8].

In general, enterprise innovation ecosystem element when decisions will have on application efficiency DEA model the impact of such evaluation model has a certain instability, relevant technical staff must be sensitivity analysis, this time, researchers will DEA mode input elements of a calculation, to enable it to carry out sensitivity analyzes innovation scale enterprises, and then draw conclusions benefits. The sensitivity of each decision unit is not the same, the most sensitive factor is X1 and X3 [9].

First, if the removal of the sensitivity factors X1 strong corporate eco-innovation system will be great changes, but also affect the overall efficiency of the values of a plurality of decision making units, but there are significant changes in the decision-making unit only few can fully cash innovative technology applications in which the amount of investment and innovation funds is very large.

Second, if the factors of X2 is removed, it will affect more than a dozen decision making unit to the overall efficiency of the value changes, to a certain extent, can improve the efficiency of enterprise innovation, the process again, the application is extremely important talent of.

Finally, if the factors of X3 removed, it will cause the entire enterprise eco-innovation system affect its overall efficiency values change significantly, indicating that the enterprise in the implementation of innovation should be useful to other types of research institutions and laboratories a lot of capital investment. Meanwhile, the entire ecosystem of enterprise system innovation, funding of other factors are also more necessary to pay attention to human resources development and introduction of experimental techniques, thereby enhancing innovation capability of enterprises to make toward a better direction.

Finally, in the process of enterprise innovation ecosystem, the input and output elements of capital is more important, a direct impact on decision-making unit, however, corporate eco-innovation system sensitivity of each unit has some differences this time enterprises should be based on different variations and differences in the various types of integrated enterprise resource advantages of a strong, thereby enhancing the efficiency of resource allocation.

\section{Implementing Countermeasures of the New Enterprise Innovation Ecosystem under Normal Autonomous Strategy}

Enterprises ecological innovation system to achieve independent innovation strategy, asked the staff to consider the issue from many angles, under normal circumstances, it is a public relations point of view and the microscopic point of view, and at the same time, under the guidance of theoretical innovation ecosystem, companies should summarize more good competition experience, to a certain extent, can effectively enhance the status of the enterprise ecosystem. Therefore, enterprises should pay attention to investment in human resources, material resources and financial resources, guarantee that the enterprise ecosystem development as the basic starting point, choose a good innovative approach, combined with the current characteristics of the enterprise, maximize and close them in the enterprise resource, thus achieving a complementary role in strengthening the innovation capacity of enterprises. In determining the enterprise ecosystem after independent innovation strategy, managers should summarize the law of development of enterprises, and then select the appropriate innovative ways to further enhance their core competitiveness. Under the new normal background, innovation pathway enterprise innovation ecosystem include the following: 
First, to do enterprise's internal research and development to ensure that you can better enhance the production capacity. Second, we must pay attention to the non-R \& D department of the enterprise, in order to lead mainstream users, and thus enhance their robustness and enhance their creativity. Again, for suppliers and competitors must be reasonable research, optimizing cost control based on the work, to enhance their competitive strength. Finally, to make the investment work of the Organization, and thus achieve the relevant objectives.

Under the new normal background, enterprises are to process innovation ecosystems, to enhance their capacity for independent innovation, we must do the following work: First, the enterprise should be institutional mechanisms for reform and innovation can build a innovation and technology development, and to improve the level of scientific and technological development, and actively facing international challenges. Second, to establish a correct sense of innovation. Enterprises in order to effectively enhance their capability of independent innovation, we should establish a correct sense of innovation, guide enterprises to individual officers when innovation. Third, increase investment in science, invest a lot in research funding on the basis of enhanced cooperation between enterprises and between enterprises, thereby enhancing the overall strength of enterprises.

\section{Conclusion}

In the process of enterprise innovation ecosystem, the relevant managers should pay attention to the development of independent innovation strategy of enterprises situation, according to the status of enterprises, implementation of innovation, the introduction of foreign advanced technology, innovative systems to improve the ecological environment.

\section{References}

[1] Gao Li. Qinghai SME Innovation Development of new economic normal background [J]. Development of Qaidam, 2015 (6): 23-25.

[2] Liang Ying. Innovative research under the new normal financial institutions small and micro enterprises - in Taizhou Branch of China Construction Bank Case Study [J]. contemporary economy, 2015 (14): 24-26.

[3] Li Zheng. Yan under the "new normal" private enterprise, innovation-driven development strategy [J]. Theory, 2015 (10): 32-39.

[4] Fan Hongyan. Innovation Research Business Models Small agricultural and forestry enterprises - Agriculture and Forestry Science and Technology Co., Ltd. Hebei Desheng Case [D]. Hebei Agricultural University, 2015.

[5] Bai Lichen. Ecological innovation and entrepreneurship and create a favorable environment for enterprise development and economic growth revitalize [J]. Technology Industry of China, 2016 (1): 11.

[6] Lin Yuanchun. Innovation and entrepreneurship ecosystem service chain Lin Yuanchun: Theoretical Concept and Policy Implications [J]. Regional Economic Review, 2015 (3): 64-69.

[7] Qian Yujuan, Guo Chao. Ecological Layout car finance [J]. China Economic Information, 2015 (3): 44-45.

[8] Cao Cuizhen. Green Resources Enterprise Innovation and Competitive Advantage [D]. Shanxi University of Finance and Economics, 2015.

[9] He Qin, Meng Quan, Li Qian. Labor relations in enterprises under the New Economic Risk Prediction of normal - Survey data is based on 245 companies [J]. China Human Resources Development, 2015 (11): 94-102,112. 